\title{
Aggressive angiomyxoma of the vulva: case report
}

\author{
Angiomixoma agressivo da vulva: relato de caso \\ José Carlos Castelo Branco Ribeiro ${ }^{1 \dagger}$, Sabas Carlos Vieira ${ }^{2}$, Benedito Borges da Silva ${ }^{2}$, \\ Lina Gomes dos Santos ${ }^{2}$, Pedro Vítor Lopes Costa $^{2}$, Lia Andréa Costa da Fonsêca ${ }^{2}$
}

\begin{abstract}
Female patient, 42-years-old, complaining of difficulty in urinating and swelling in the vulvar area for one year. Her gynecological examination showed extensive injury in the vulvar region and the biopsy done was inconclusive. The removal of the lesion was conducted. After the procedure, the patient remains free of recurrence for 15 months. This case highlights the need to consider angiomyxoma in the differential diagnosis for tumors of unknown cause in the vulvar region.
\end{abstract}

Keywords: Myxoma/diagnosis; Vulvar neoplasms; Case reports

\section{RESUMO}

Paciente do gênero feminino, 42 anos, com queixas de dificuldade ao urinar e aumento de volume na região vulvar há 1 ano. Ao exame ginecológico, apresentava extensa lesão na região vulvar. Biópsia da lesão foi inconclusiva. Realizou-se a exérese da lesão. A paciente permanece livre de recorrências há 15 meses. Este caso destaca a necessidade de considerar 0 angiomixoma no diagnóstico diferencial de massas de causa desconhecida na região vulvar.

Descritores: Mixoma/diagnóstico; Neoplasias vulvares; Relatos de casos

\section{INTRODUCTION}

Aggressive angiomyxoma (AA) is a rare tumor with higher risk of infiltration and recurrence. ${ }^{(1)}$ This tumor pathogenesis is unclear. ${ }^{(2)}$ It occurs predominantly in vulvo-vaginal, perineal and groin region, and the diagnosis is made by histopathology examination. Treatment must be exeresis of the tumor such as GnRH agonists used with adjunct therapy. ${ }^{(3,4)}$

The AA was first described by Steeper and Rosai in 1983. ${ }^{(4)}$ In 2009, less than 250 cases of angiomyxoma was described, which highlights the rarity of this disease. ${ }^{(3)}$ Most of cases reported have been in women at reproductive age and those in fourth decade of life. The AA can affect women and men in a proportion of $6: 10^{(4,5)}$

We report a rare disease. From the best of our knowledge only 74 cases of AA were reported in the literature so far.

\section{CASE REPORT}

A 42-year-old woman (G3P3(v)A0) sought the gynecology outpatient unit of the Hospital Getúlio Vargas de Teresina in Piaui, Brazil, complaining of difficult to void and tumor in vulvar region for one year.

Gynecological examination showed a large mass located in the groin and vulvar region that caused a decrease of vaginal cavity and bulging on its posterior wall (Figure 1).

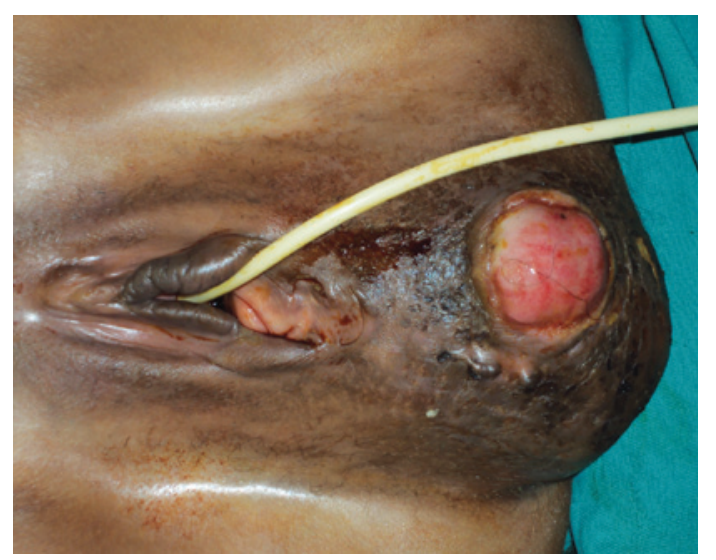

Figure 1. Pre-operative appearance. Large mass located in perineal and vulvar region

\footnotetext{
${ }^{1+}$ In memoriam; Instituto de Doenças Tropicais Nathan Portella, Teresina, PI, Brazil.

${ }^{2}$ Universidade Federal do Piaú, Teresina, PI, Brazil.

Corresponding author: Sabas Carlos Vieira - Rua Félix Pacheco, 2159 room 305 - Centro - Zip code: 64001-160 - Teresina, PI, Brazil - Phone: (55 82) 3226-1555 - E-mail: sabas.vieira@uol.com.br 
A biopsy of the lesion was done and showed proliferation of fibroblast and myofibroblast cells without atypia on abundant collagenous matrix with blood vessels in between. Absence of mitotic activity and/or necrosis.

Computed tomography of groin region showed expansive pelvic lesion with hemorrhagic necrosis area in between, well-delimited, and with extension to vaginal route and presacral region, which determined bulging of circumscribed structures without signals of invasion to myoadipose plans.

A complete exeresis of the lesion was conducted $(30 \times 20 \times 10 \mathrm{~cm})$ located in vulvoperineal region that extended to posterior vaginal wall and to anterior wall of rectus (Figure 2). The synthesis of the surgical defect was done with approximation of deep plans and suture of vulvoperineal region. A suction drain was used and it was removed on fifth day after the surgery. The patient was treated with metronidazol and ciprofloxacine for 14 days and evolved without any intercurrences.

The histopathological exam of the specimen showed deep angiomyxoma (Figure 3).

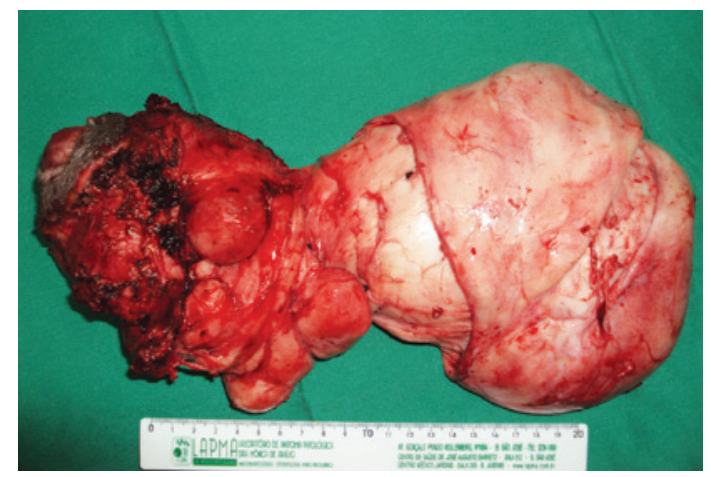

Figure 2. Macroscopic appearance of tumors, which measured $18 \times 11 \times 13 \mathrm{~cm}$ with undulating external surface and grayish-white, and lobulated cut surface, brilliant and grayish-white with myxoid areas

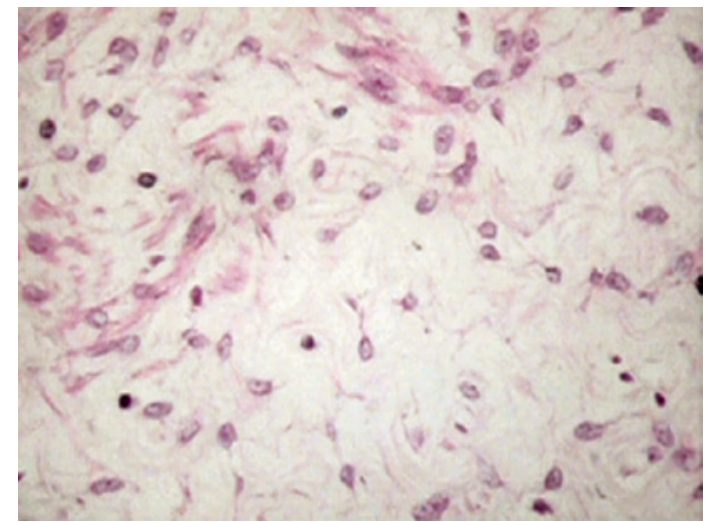

Figure 3. Microscopic appearance of the tumor. Vessels of medium size and thickened wall, involved by stromal cell layer of myxoid apperance. Hematoxylin and eosin $200 \mathrm{X}$
Currently, the patient remains asymptomatic without evidence of disease for 15 months after the surgery.

\section{DISCUSSION}

The AA is wrongly diagnosed in $80 \%$ of cases. Classic presentation is a mass of slowing growth, painless, located in vulva, perineum and buttock. Patients often report that the mass is asymptomatic.

The pathogenesis of vulvar AA is poorly extended, however, genetic changes in short arm of the chromosome 12(12q) has been implicated as the cause. ${ }^{(6)}$ The histopathology exam is the gold standard diagnosis and, often, shows vessels of medium size and thickness wall, rounded by layer of stromal cells of myxoid appearance. ${ }^{(4)}$ Histologically this tumor is hypo-or moderately cellular being fusiform or stellar cells in between the myxoid matrix of mucopolysaccharides, involving a number of vessels of small and medium size - being this latter, sometimes, of thickness and hyalinized wall.(7) In our case, the surgical specimen consisted of a tumor weighting $1,326 \mathrm{~g}$ and measuring $18 \times 11 \times 13 \mathrm{~cm}$ with undulating external surface, brilliant and grayish-white with myxoid areas. Under microscope middle size vessels were seen and a thickened wall, involved by stromal cells of myxoid appearance. Immunohistochemically, tumoral cells show immunoreactivity, at least focally, for specific vimentin and muscle-specific actin. The desminpositivity is controversial. There are immunonegativity for carcino-embrio antigen, cytokeratin, VIII factor and S100 protein. ${ }^{(7)}$

Several modalities of imaging exams have been used to identify and describe AA. The ultrasonography usually reveals a cystic and hypoechoic mass. In general, computed tomography reveals a tumor with welldefined borders with low attenuation than muscles, probably due to loose myxoid stroma and high aqueous content of such tumor. In relation to muscles sings in magnetic resonance, the AA show a isointense signal in T1 and hyperintense in T2 weighted image. ${ }^{(6)}$ Imaging studies are important in pre-operative evaluation since the tumor extension is frequently underestimated by physical examination. The early detection of recurrences can also be increased by inclusion of imaging studies in the follow-up protocol. ${ }^{(1)}$

Multiple modalities of treatment have been described, however, the complete surgical exeresis, when requested, must be considered. Partial exeresis can be justified when a high surgical morbidity is anticipated. Unfortunately, recurrences can occur, even with negative surgical margins. Several surgical or clinical approach can be used to treat this disease recurrence. The exeresis is still the best 
treatment, but gonadotropin-releasing hormone $(\mathrm{GnRH})$ antagonist has been described to prevent recurrence in isolated cases. ${ }^{(4)}$ Most of angiomyxomas show positivity to receptors of estrogen and progesterone, being probably hormone-dependent. For this reason, hormonal manipulation is believed to be a viable option for treatment. Analogs of GnRH have been used in some few cases of premenopausal women, but this tumor can regrowth once the therapy is discontinued. The pre-operative reduction of tumors using analogs of $\mathrm{GnRH}$ can increase the chances of complete excision and reduce the radicality of the surgical procedure. ${ }^{(3)}$ Adjuvant hormonal treatment has been also described with tamoxifen and raloxifene with several degrees of success - from no response to complete remission of primary or recurrence of AA. Radiotherapy and chemotherapy have been used as adjuvant therapies, but it is less likely that they are useful, because the AA has low mitotic activity. The arterial embolization has been also reported, but, generally, it is not conducted, once these tumors are fed by several vessels. Because of its rarity, the role of biopsy of sentinel lymph nodes and lymphadenectomy in AA is still unclear. Although the great availability of a number of treatment, the recurrence of AA is higher than $72 \%$.(6)

No guidelines exist on the postoperative management of vulvar AA. However, because of high rate of recurrence and potential morbidity associated with non-diagnosed recurrences, several authors have recommend periodic evaluations with physical exam and magnetic resonance for up to 15 years after the treatment. ${ }^{(6)}$

Angiomyxoma must be always considered in differential diagnosis of mass in the vulva, perineum and buttocks. The histopathological exam is the best way to conduct the definitive diagnosis. Treatment must be exeresis of the tumor with agonists of GnRH with adjunct therapy. ${ }^{(4)}$

\section{REFERENCES}

1. Fetsch JF, Laskin WB, Lefkowitz M, Kindblom LG, Meis-Kindblom JM. Aggressive angiomyxoma: a clinicopathologic study of 29 female patients. Cancer. 1996; 78(1):79-90.

2. NucciMR, Weremowicz S, Neskey DM, Sornberger K, TalliniG, Morton CC, et al. Chromosomal translocation t $(8 ; 12)$ induces aberrant HMGIC expression in aggressive angiomyxoma of the vulva. Genes Chromosomes Cancer. 2001; 32(2):172-6.

3. Haldar K, Martinek IE, Kehoe S. Aggressive angiomyxoma: a case series and literature review. Eur J Surgical Oncol. 2010;36(4):335-9. Review.

4. Faber B, Dunwoody R, Kamal N. A rarer case of a rare disease: aggressive angiomyxoma (AAM) in a sixteen year old. West London Med J. 2013;5(1):1-5.

5. Gonzaga LF, Freitas FC, Tavares JM. Aggressive vaginal angiomyxoma mimicking urethral tumor. Int Braz J Urol. 2005;31(5):475-6.

6. Elkattah R, Sarkodie 0, Otteno H, Fletcher A. Aggressive angiomyxoma of the vulva: a précis for primary care providers. Case Rep Obstet Gynecol. 2013; 2013:183725.

7. Jardim 0, Matos R, Falcão F, Dinis M, Oliveira C. Angiomixoma agressivo da vulva. Acta Med Port. 2001;14(5-6):507-10. 